\title{
Molecular Assisted Selection for Pollination-Constant and Non-Astringent Type without Male Flowers in Spanish Germplasm for Persimmon Breeding
}

\author{
Manuel Blasco ${ }^{1}$, Francisco Gil-Muñoz ${ }^{2}$, María del Mar Naval ${ }^{1}$ and María Luisa Badenes ${ }^{2, *(D)}$ \\ 1 CANSO, Mestre Serrano, 1, 46250 L'Alcúdia, Valencia, Spain; blasco_manvil@externos.gva.es (M.B.); \\ naval_marmer@gva.es (M.d.M.N.) \\ 2 Instituto Valenciano de Investigaciones Agrarias, CV 315 km 10,5., 46113 Moncada, Valencia, Spain; \\ gil_framuna@externos.gva.es \\ * Correspondence: badenes_mlu@gva.es
}

Received: 14 July 2020; Accepted: 7 August 2020; Published: 11 August 2020

\begin{abstract}
Persimmon (Diospyros kaki Thunb) species is a hexaploid genotype that has a morphologically polygamous gyonodioecious sexual system. $D$. kaki bears unisexual flowers. The presence of male flowers resulted in the presence of seeds in the varieties. The fruits of persimmon are classified according to their astringency and the pollination events that produced seeds and modify the levels of astringency in the fruit. The presence of seeds in astringent varieties as pollination variant astringent (PVA), pollination variant non-astringent (PVNA) and pollination constant astringent (PCA) resulted in fruits not marketable. Molecular markers that allow selection of the varieties according to the type of flowers at the plantlet stage would allow selection of seedless varieties. In this study, a marker developed in D. lotus by bulk segregant analysis (BSA) and amplified fragment length polymorphism (AFLP) markers, named DISx-AF4, has been validated in a germplasm collection of persimmon, results obtained agree with the phenotype data. A second important trait in persimmon is the presence of astringency in ripened fruits. Fruits non-astringent at the ripen stage named pollination constant non-astringent (PCNA) are the objective of many breeding programs as they do not need removal of the astringency by a postharvest treatment. Astringency in the hexaploid persimmon is a dominant trait. The presence of at least one astringent allele confers astringency to the fruit. In this paper we checked the marker developed linked to the AST gene. Our goal has been to validate both markers in germplasm from different origins and to test the usefulness in a breeding program.
\end{abstract}

Keywords: persimmon; sex determination; fruit astringency; molecular markers

\section{Introduction}

Persimmon (Diospyros kaki Thunb) species is a hexaploid genotype that has a morphologically polygamous gyonodioecious sexual system [1]. D. kaki bears unisexual flowers, as do other Diospyros species. There are genotypes that bear only female flowers and genotypes bearing male and female flowers [2]. Furthermore, varieties bearing only male flowers were described in China [3] and occasional male flower formation was reported in varieties that usually bear only female flowers [4]. In addition to the unisexual flowers, some varieties or genotypes bear hermaphrodite flowers; however, these flowers do not function fully as female flowers [5]. Most of the commercial varieties present only female flowers [6], however the presence of the male flowers type is important in two scenarios: first when the production of seeded fruits is convenient and second in breeding activities in which crosses are requested.

The fruits of persimmon are classified according to their astringency and the pollination events that resulted in different types of fruits. The PCNA (pollination constant non-astringent) varieties 
are always not astringent at maturity regardless of pollination events and the presence or absence of seeds in the fruit. The presence of male flowers in these varieties is most convenient since it allows pollination and produces seeded fruits that increase the fruit size and weight. In Japan, the presence of seeds in the fruit does not affect the consumers demand [7]. However, in Europe and western countries consumers prefer seedless fruits.

Three additional variety types can be distinguished: PVNA-type (pollination variant non-astringent), which are non-astringent varieties when seeds are present; PVA-type (pollination variant astringent), which are astringent varieties in most parts of the fruit and non-astringent around the seeds if they are present, and PCA-type (pollination constant astringent), which are astringent varieties regardless the presence of seeds. The loss of astringency in these types of persimmons is associated to the ability of the seeds to produce acetaldehyde. This production resulted in browning of the flesh around the seeds (Figure 1), which interfere with the postharvest treatment for removing the astringency in the fruit, all together the PVA and PCA type fruits are unmarketable if they are pollinated and the fruits present seeds [8,9]. In PVA and PCA varieties it is crucial to avoid pollination, hence the presence of male flowers in the variety and in the vicinity of the crop should be avoided. The ability of the production of male flowers is a genetic trait that should be determined in the varieties for avoiding seeds in astringent varieties or improving the presence of them in non-astringent varieties.
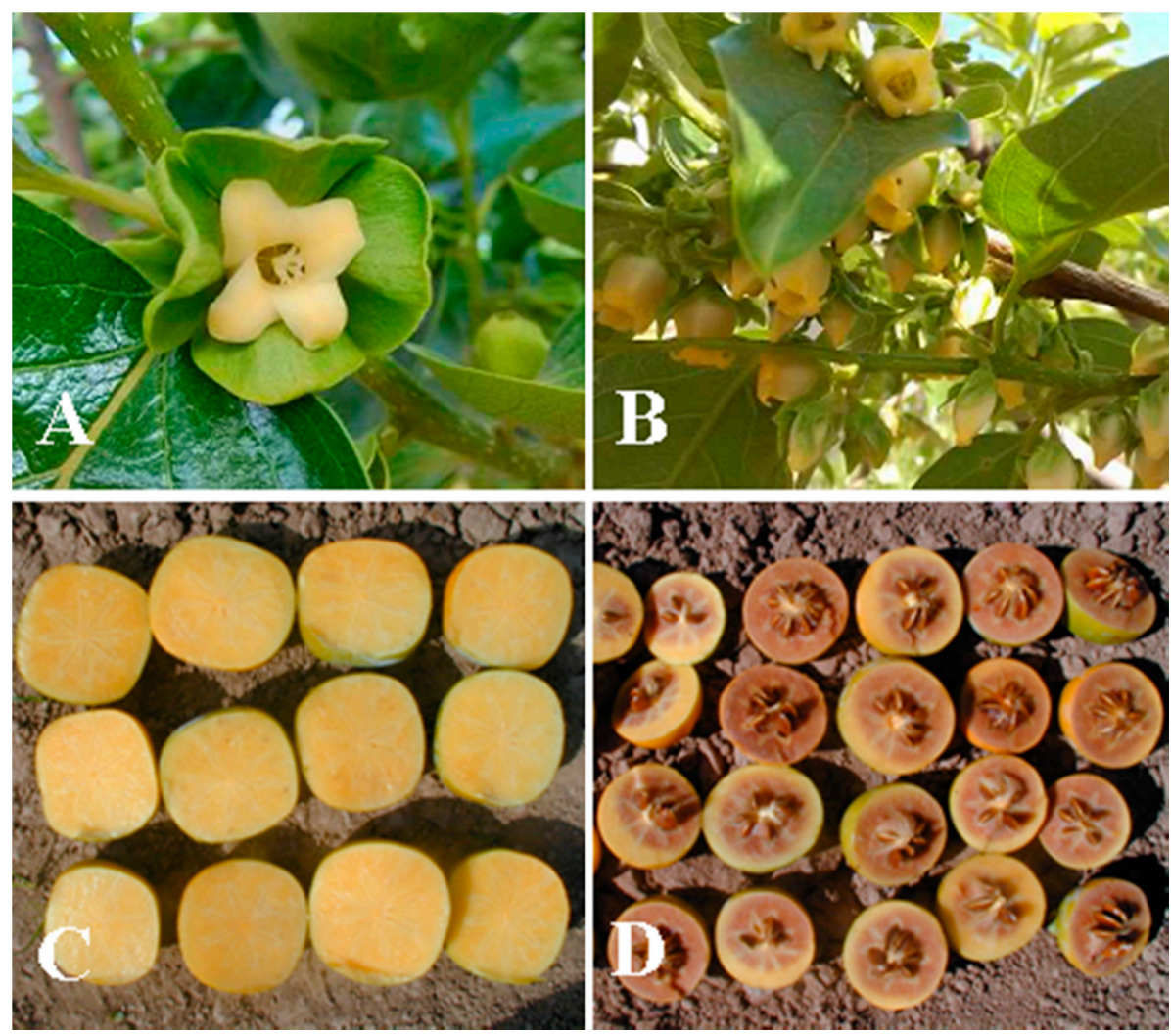

Figure 1. Phenotypes of the traits selected. (A,B) flowers from the variety 'Cal Fuyu', female and male respectively and (C,D) results of pollination on astringent fruits from 'Rojo Brillante' a pollination variant astringent (PVA) variety: (C) parthenocarpic non-pollinated fruits and (D) pollinated fruits in which presence of seeds resulted in no marketable fruits.

Elucidation of the genetic and molecular basis of sex expression in D. kaki leading to the development of molecular markers would allow selection of the varieties according to the type of flowers, being a great contribution for persimmon production and Diospyros breeding. The hexaploidy of $D$. kaki made elucidation of this question more difficult than in diploid genotypes. Since the genus includes more than 700 species with different levels of polyploidy, the diploid Diospyros lotus was 
used for investigation of the sex expression into the genus [10]. These authors described the model of inheritance and developed molecular markers associated to sex expression. Later small RNA acting as a sex determinant was identified [11]. Development of markers used the bulk segregant analysis (BSA) and amplified fragment length polymorphism (AFLP). An AFLP marker identified as DISx-AF4 was sequence-characterized and converted into the sequence characterized amplified region (SCAR) [10]. In this study the marker has been tested in a germplasm selection of varieties phenotyped for sex expression and a backcross population obtained at Instituto Valenciano de Investigaciones Agrarias (IVIA). The results provide evidence of the usefulness of molecular marker assistance in identifying the genetic potential of production of male flowers in persimmon, an important trait in breeding.

PCNA varieties are highly desired because their mature fruits are not astringent, as they stop accumulating tannins at early steps of fruit development [12]. In Japanese varieties, the PCNA trait is recessive to the non-PCNA trait [13] and is controlled by a single locus, AST [14]. Due to persimmon being a hexaploid, the PCNA type should contain six recessive ast alleles [15]. In breeding programs aimed at obtaining PCNA cultivars, the hexaploidy of persimmon along with the recessive inheritance of the non-astringency trait led to breeders to develop crosses that involved only PCNA genotypes. Consequently, several generations of crosses between PCNA genotypes along with the low genetic diversity of this group of persimmons resulted in families with a high rate of inbreeding and plenty of the problems derived from this fact. To avoid inbreeding, the programs need to use non-astringent cultivars in the crosses, but the rate of PCNA obtained could be very low depending on the number of dominant AST alleles carried by the parents selected. In a backcross $\mathrm{BC}_{1}$, the expected proportion of PCNA offspring from a non-PCNA $F_{1}$ parent with one dominant AST, two or three is 50,20 or $5 \%$, respectively, under an autohexaploid model. In this context, it is of high interest to be able of selecting PCNA types and non-PCNA types in the families obtained at the plantlet stage. The alternative is to select the type of the fruits in the fields after a juvenile period of four years minimum, which is extremely costly and has a low efficiency.

Many efforts have been made to target the region linked to AST [14,16-18]. The most promising results were obtained in a study that identified a region tightly linked to the AST gene [19]. These authors developed a multiplex PCR method based on primers developed from the region identified, highly reliable that allowed detecting recessive and dominant alleles. These primers have been used to test a group of varieties [15]. The region contains microsatellites that allow distinguishing 12 different alleles from 14 non PCNA genotypes. More than 200 accessions and several crosses between PCNA and non-PCNA genotypes were analyzed [20]. Based on the number of fragments detected per individual these authors were able to determine the dominant (AST) and recessive (ast) alleles in the hexaploid persimmon germplasm.

Using this methodology, in this paper we applied molecular assisted selection for discriminate PCNA cultivars and seedlings from different segregated populations obtained in the frame of the IVIA breeding program. The markers for both traits were developed from Japanese varieties, our goal is to validate the markers in a set of germplasm from different origins and different type of astringency and applied them to the IVIA breeding program, in which the involvement of varieties from Mediterranean origin is relevant.

\section{Materials and Methods}

\subsection{Plant Materials}

\subsubsection{Validation of AST and DISx-AF4S Markers}

Molecular markers developed for sex expression and type of astringency in persimmon were studied in a set of 42 accessions (Table 1) from the persimmon germplasm collection maintained at IVIA, Moncada, Spain $(39.588741,-0.394848)$. The accessions were phenotyped regarding the presence of male flowers. The phenotype of astringency type was known from previous germplasm characterization [21,22]. 
Table 1. Plant material studied, origin, astringency type, genotype of AST marker, flower type and genotype of the DISx-AF4S marker.

\begin{tabular}{|c|c|c|c|c|c|c|c|c|c|c|c|}
\hline Variety & Origin & Type $^{1}$ & AST $^{2}$ & Flowers ${ }^{1}$ & D1Sx-AF4S ${ }^{2}$ & Variety & Origin & Type $^{1}$ & AST $^{2}$ & Flower $^{1}$ & D1Sx-AF4S ${ }^{2}$ \\
\hline Anheca & Spain & PCA & + & 우 & - & Kawabata & Japan & PCNA & - & ㅇ & - \\
\hline Ferrán-12 & Spain & PCA & + & q & - & Koda Gosho & Japan & PCNA & - & q & - \\
\hline Reus-6 & Spain & PCA & + & q & - & Maekawa jiro & Japan & PCNA & - & 우 & - \\
\hline Tomatero & Spain & PCA & + & q & - & Mukaku jiro & Japan & PCNA & - & q & - \\
\hline Costata & Italy & PCA & + & q & - & O'Gosho & Japan & PCNA & - & 우 & - \\
\hline Lycopersicon & Italy & PCA & + & 우 & - & Suruga & Japan & PCNA & - & 우 & - \\
\hline Aizumishirazu-A & Japan & PCA & + & 아 & - & Yamato Gosho & Japan & PCNA & - & 안 & - \\
\hline Fuji & Japan & PCA & + & ๆ & - & Bétera-2 & Spain & PVA & + & q & - \\
\hline Korea Kaki & Japan & PCA & + & q & - & Reus-15 & Spain & PVA & + & 우 & - \\
\hline Yokono & Japan & PCA & + & o & - & Xato de Bonrepós & Spain & PVA & + & o & - \\
\hline Cal Fuyu & Japan & PCNA & - & $+/ 0^{7}$ & + & Aizumishirazu-B & Japan & PVA & + & ㅇ & - \\
\hline Fau Fau & Japan & PCNA & - & $\$ / 0^{7}$ & + & Atago & Japan & PVA & + & q & - \\
\hline Fukuro Gosho & Japan & PCNA & - & $+/ 0^{\pi}$ & + & Hiratanekaki & Japan & PVA & + & 우 & - \\
\hline Fuyu & Japan & PCNA & - & ㅇ & - & Hiratanenashi & Japan & PVA & + & 아 & - \\
\hline Giant Fuyu & Japan & PCNA & - & q & - & Maru & Japan & PVA & + & $\% / 0^{\pi}$ & + \\
\hline Hana fuyu & Japan & PCNA & - & 우 & - & Tone Wase & Japan & PVA & + & q & - \\
\hline Hana Gosho & Japan & PCNA & - & $+/ 0^{x}$ & + & Pakistan Seedless & Pakistan & PVA & + & o & - \\
\hline Ichikikei Jiro & Japan & PCNA & - & क & - & Agakaki & Japan & PVNA & + & $\% / 0^{\pi}$ & + \\
\hline Isahaya & Japan & PCNA & - & ㅇ & - & Castellani & Italy & PVNA & + & $q$ & - \\
\hline
\end{tabular}

${ }^{1}$ Data from phenotyping. ${ }^{2}$ Data from genotyping. 


\subsubsection{Marker Assisted Selection}

Marker assisted selection was made on 12 segregated populations obtained from ('Rojo Brillante' $\times$ 'Cal Fuyu') $\times$ 'Cal Fuyu' in 2016. The backcross was made using 'Rojo Brillante' a high-quality variety astringent (PVA) and 'Cal Fuyu' a PCNA variety with male flowers. Both parents were selected based on agronomic characteristics and adaptability to the Mediterranean environment [21].

Segregated populations screened and individuals per population are described in Table 2. All progenies and seedlings obtained were maintained in orchards at CANSO's Experimental Station, L'Alcudia, Valencia, Spain (39.189086, -0.542067).

Table 2. Results of genotypes analyzed by molecular markers. Number of offspring with the astringent allele (AST), with the DISx-AF4S allele, with AST + DISx-AF4S (not selected) and number of offspring with the absence of both markers (genotypes selected).

\begin{tabular}{cccccc}
\hline & & \multicolumn{5}{c}{ Number of Offspring } \\
\cline { 3 - 5 } Progeny & Total & AST + & D1Sx-AF4S + & $\begin{array}{c}\text { AST }+ \\
\text { D1Sx-AF4S }+\end{array}$ & $\begin{array}{c}\text { AST - } \\
\text { D1Sx-AF4S - }\end{array}$ \\
\cline { 3 - 6 } & & & & $22(22.2)$ & $21(21.2)$ \\
F-1.34 & 99 & $61(61.6)$ & $43(39.4)$ & $28(43.1)$ & $11(16.9)$ \\
F-1.50 & 65 & $39(60.0)$ & $43(66.2)$ & $4(8.5)$ & $14(29.8)$ \\
F-1.52 & 47 & $13(27.7)$ & $24(51.1)$ & $3(60.0)$ & $1(20.0)$ \\
F-2.27 & 5 & $4(80.0)$ & $3(60.0)$ & $7(63.6)$ & $1(9.1)$ \\
F-4.19 & 11 & $8(72.7)$ & $9(81.8)$ & $10(16.4)$ & $20(32.8)$ \\
F-4.24 & 61 & $20(32.8)$ & $31(50.8)$ & $4(10.5)$ & $19(50.0)$ \\
F-4.35 & 38 & $14(36.8)$ & $9(23.7)$ & $3(5.8)$ & $24(46.2)$ \\
F-4.49 & 52 & $14(26.9)$ & $17(32.7)$ & $4(33.3)$ & $0(0.0)$ \\
F-5.32 & 12 & $10(83.3)$ & $6(50.0)$ & $5(18.5)$ & $5(18.5)$ \\
F-5.34 & 27 & $11(40.7)$ & $16(59.3)$ & $4(23.5)$ & $0(0.0)$ \\
F-5.36 & 17 & $12(70.6)$ & $9(52.9)$ & $3(42.9)$ & $2(28.6)$ \\
F-5.41 & 7 & $5(71.4)$ & $3(42.9)$ & $97(22.0)$ & $118(26.8)$ \\
total & 441 & $211(47.8)$ & $209(47.4)$ & & \\
\hline
\end{tabular}

Numbers in parentheses are the rate (\%) of corresponding offspring in each progeny.

\subsection{Methods}

\subsubsection{DNA Isolation}

Young fully expanded leaves were collected from trees and kept at $-20^{\circ} \mathrm{C}$ until DNA isolation. DNA was isolated according to the CTAB method described in [23] with minor modifications [24].

\subsubsection{Molecular Markers Analysis}

The capacity of producing male flowers was checked with the sequence characterized amplified region (SCAR) marker 'DISx-AF4S' [10], primers used were: forward (DISx-AF4-3F; 5'-ACA TCC AAA GTT CTG GAG AAT CA-3') and reverse (DISx-AF4-3R; $5^{\prime}$-ATT GGT GCT TGG TCA AAC ATA TC- $3^{\prime}$ ).

Determination of PCNA genotypes used the primers described in [19] PCNA-F (CCCCTCAGTGGCAGTGCTGC) and 5R3R (GAAACACTCATCCGGAGACTTC).

Polymerase chain reactions (PCRs) were performed in a final volume of $20 \mu \mathrm{L}$ containing $1 \times$ of DreamTaq Buffer (Thermo Fisher Scientific, Vilnius, Lithuania), $0.1 \mathrm{mM}$ of each dNTPs (Promega, Madison, WI, USA), $20 \mathrm{ng}$ of genomic DNA and $1 \mathrm{U}$ of DreamTaq polymerase (Thermo Fisher Scientific, Vilnius, Lithuania). The PCR program consisted of pre-denaturation at $94{ }^{\circ} \mathrm{C}$ for $2 \mathrm{~min} ; 35$ cycles at $98^{\circ} \mathrm{C}$ for $15 \mathrm{~s}, 60^{\circ} \mathrm{C}$ for $20 \mathrm{~s}$ and $72{ }^{\circ} \mathrm{C}$ for $1 \mathrm{~min}$; followed by a final extension at $72{ }^{\circ} \mathrm{C}$ for $10 \mathrm{~min}$. PCR products were separated by electrophoresis on $1.5 \%$ agarose gels in $0.5 \times$ TAE buffer and visualized with GelRED ${ }^{\circledR}$ (Sigma-Aldrich, St. Louis, MI, USA). 


\section{Results and Discussion}

\subsection{Marker Assisted Selection Validation: Production of Male Flowers}

A set of accessions belonging to the persimmon germplasm bank were phenotyped for the presence of male flowers and later genotyped with the marker DISx-AF4S [10] to test the accuracy of the marker for Molecular Assisted Selection (MAS). Results of the genotype agreed with the results of the phenotype (Table 1), non-discrepancies were observed. The capacity of developing male flowers was clearly stated by the presence of the amplified band ( $320 \mathrm{bp}$ ). Figure $2 \mathrm{a}$ shows the results on an agarose gel of the presence of male flowers in the genotypes 'Agakaki', 'Cal Fuyu' and the selection 'F-1.34' from the IVIA breeding program. Total correlation between the phenotype and the presence/absence of the band was obtained for all the genotypes studied (Table 1). This marker is a great advantage in breeding programs in which astringent and non-astringent genotypes are involved. The presence of male flowers in astringent varieties (PVNA, PVA and PCA) resulted in the presence of seeds in the fruit. The loss of astringency in these types of persimmons is associated to the ability of the seeds to produce acetaldehyde (Figure 3). Production of acetaldehyde is a quantitative trait in which less production by the seed resulted in higher astringency on the pulp (PCA), and high production resulted in low/none astringent flesh (PVNA) being PVA intermediate. This acetaldehyde production resulted in browning of the flesh around the seeds, which interferes with the postharvest treatment for removing the astringency in the fruit [25]. All together the PVA and PCA type fruits pollinated are unmarketable. In the case of PVNA types in which the presence of seeds browned completely the flesh (Figure 3), there are specific markets in which these varieties are accepted. However, in most of the markets, the PVNA fruits are accepted with no seeds and after removing the astringency by postharvest treatment. In all breeding programs that use astringent varieties, MAS for discriminating male flowers is very important for avoiding self-pollination and/or mix of cultivars that can cross pollinated among them and produced seeds. In breeding programs that involve non-astringent varieties the discrimination of the presence of male flowers is necessary too. Some Japanese programs look for varieties with male flowers and seeds that increase the size and setting of fruits, but in western countries, where the presence of seeded fruits is not acceptable, the presence of male flowers is discarded similarly to astringent varieties. Selection of this trait in persimmon species that have a four-year juvenile period resulted in great interest to avoid plants in the fields that will be eliminated in the future and, additionally, to avoid undesired pollination in the breeding plots.

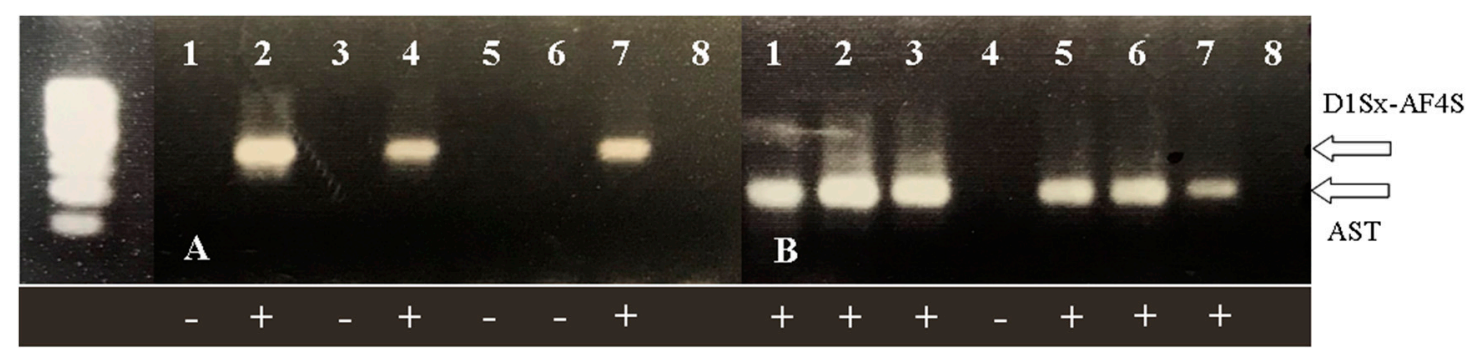

1. Rojo Brillante 2. Agakaki 3. Tone Wase 4. Cal Fuyu 5. Castellani 6. Edoichi 7. F-1.34 8. Blank

Figure 2. PCR results by electrophoresis in an agarose gel (1.5\%) vs. phenotype data; (A) D1Sx-AF4S PCR results. The (+) presence and (-) absence of male flowers from phenotype data; the DlSx-AF4S marker is present in varieties 'Agakaki', 'Cal Fuyu' and F.1-34 in agreement with the phenotype; (B) AST PCR results; (+) astringent fruits according to phenotype data and (-) non-astringent fruits (pollination constant non-astringent (PCNA)) according to phenotype data. The AST marker was present in all astringent varieties and absent in 'Cal Fuyu', a PCNA variety. 


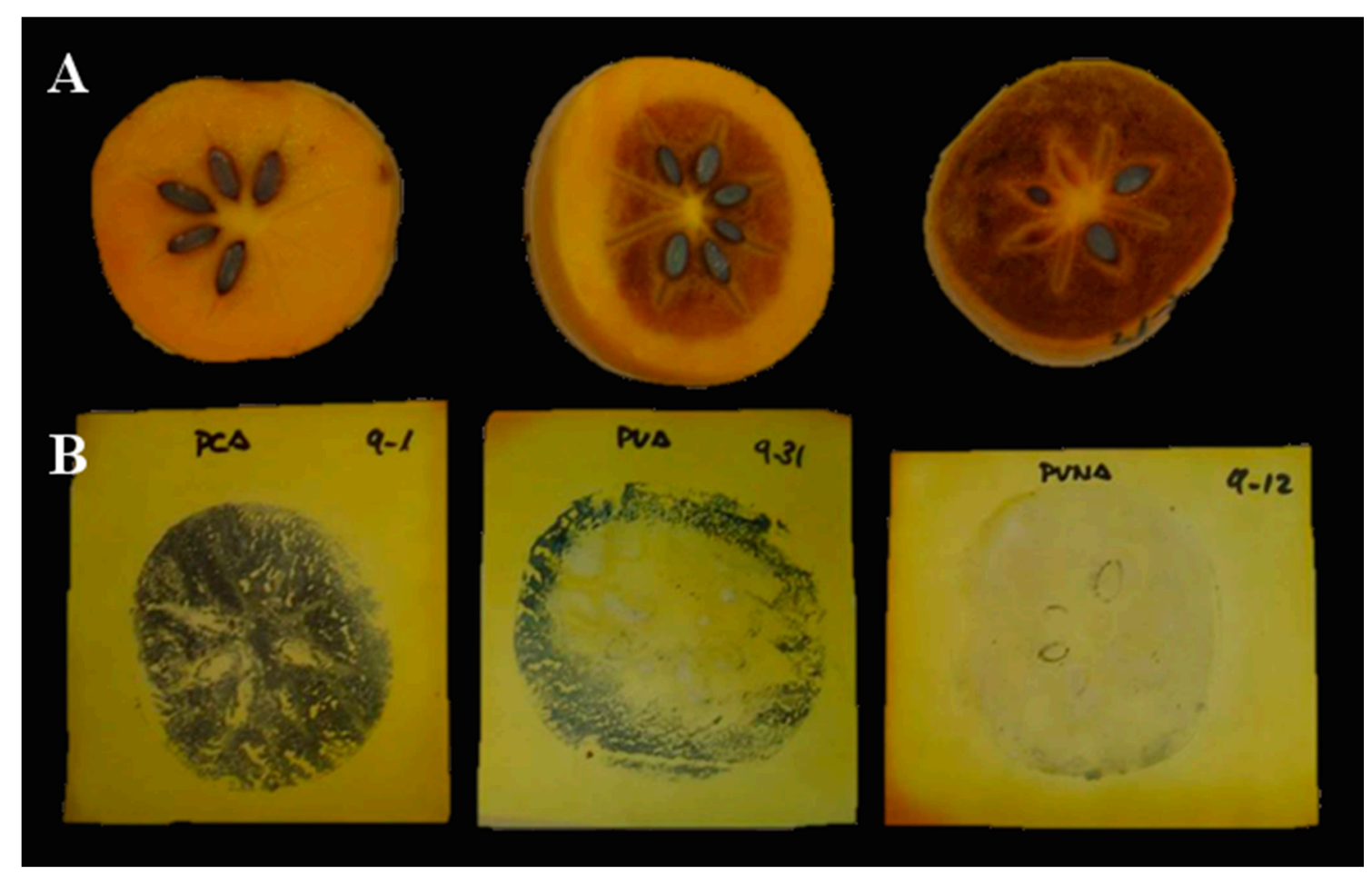

Figure 3. Three types of astringent persimmon according to the amount of acetaldehyde produced by the seed; (A) fruits of pollination constant astringent (PCA), PVA and pollination variant non-astringent (PVNA; from right to left) and (B) distribution of condensed tannins, visualized by precipitation of blue ferric chloride impregnated in a paper $[25,26]$. Fruits of PCA, PVA and PVNA (from right to left).

\subsection{Marker Assisted Selection Validation: Selection of PCNA}

In Japanese cultivars, the PCNA trait is recessive to the non-PCNA trait [13] and is controlled by a single locus, AST [14]. Due to persimmon being a hexaploid, the PCNA type should contain six recessive ast alleles [15]. Detection of at least one AST allele determines the astringency of fruit. Selection of non-astringent fruits or PCNA are the objective in most of the persimmon breeding programs currently active in the world [27-32]. In this study we validated the AST marker developed in [19] for discrimination between PCNA genotypes and the different astringent types.

Validation of AST marker was carried out in a set of cultivars from the germplasm collection with known astringency (Table 1). A total correlation between the phenotypic data of astringency and the markers obtained in the genotypes analyzed was obtained. Figure $2 b$ shows the PCR products of a set of accessions. Two PVA cultivars 'Rojo Brillante' and 'Tone Wase', three PVNA cultivars 'Agakaki', 'Castellani', 'Edoichi' and 'F-1.34' showed a clear band for AST marker. The PCNA cultivar 'Cal Fuyu' showed no amplified product.

\subsection{Marker Assisted Selection of Both Traits in the IVIA Breeding Program}

After validation of the DISx-AF4S and AST markers in a set of accessions phenotyped, we applied both markers in the breeding program for selecting the individuals of several segregated populations (Figure 4).

A total of 441 individuals belonging to 12 segregated populations obtained by a backcross that consisted in $($ PVA $\times$ PCNA $\times$ PCNA) were evaluated (Table 2). The cross $($ PVA $\times$ PCNA) was made using 'Rojo Brillante' a high-quality variety astringent and 'Cal Fuyu' a PCNA variety with male flowers. 


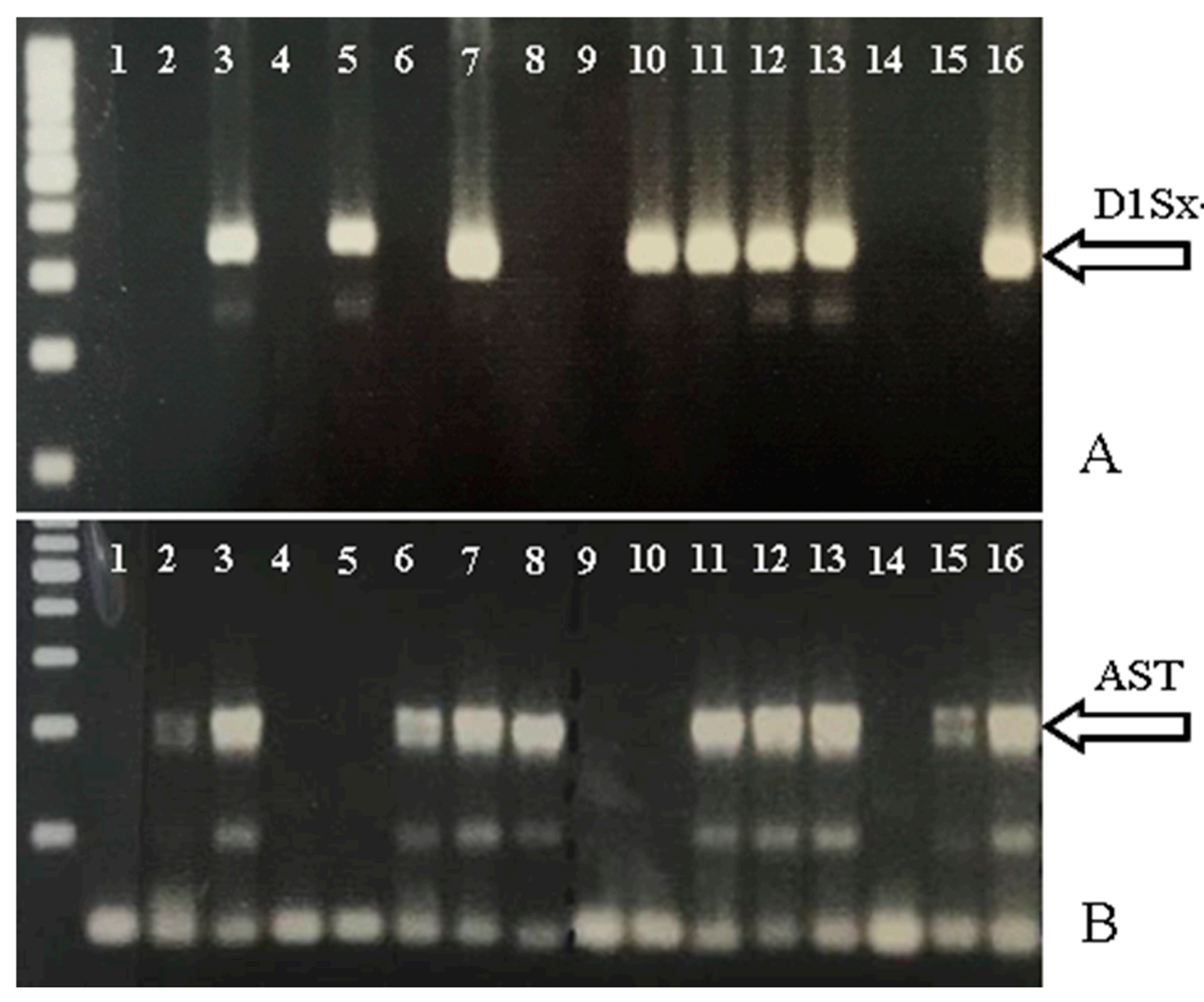

Figure 4. PCR results from agarose gel electrophoresis of 16 backcross (BC) individuals genotyped for AST and D1Sx-AF4S markers. (A) Presence of the marker (D1SX-AF4S) indicates ability for developing male flowers; (B) Absence of the marker means absence of any astringent allele (AST), which corresponds to a PCNA genotype The BC progenies are selected based on the absence of both markers, which corresponds to PCNA types without capability of the development of male flowers. Individuals 1, 4, 9 and 14 have been selected.

The astringency trait is a dominant marker and taking into account the hexaploidy of persimmon, the number of PCNA genotypes obtained in crosses that involved astringent types depends on the number of AST alleles present in the astringent parental. The validation of the AST marker was made based on different segregated families by [33]. Identification of different AST alleles was made in a set of cultivars by means of crosses with PCNA varieties, analysis of the segregation obtained and sequence of the genomic region [15]. If a non-PCNA has a single A allele (Aaaaaa) and is crossed with a PCNA individual (aaaaaa), $50 \%$ of the offspring will be astringent. In the program the $\mathrm{F}_{1}$ seedlings obtained and crossed with the PCNA 'Cal Fuyu' resulted in a different percentage of astringent genotypes. It has been demonstrated that the number of PCNA obtained depends on the allelic dose of the $\mathrm{F}_{1}$ backcrossed [17]. In this study, the number of individuals per progeny was very low for studying segregation ratios and inferred the number of $A$ alleles in the $F_{1}$ mothers. However, taking all the tested $\mathrm{BC} 1$ seedlings together the rate of astringent genotypes was around $50 \%$, which indicates that the $\mathrm{F}_{1}$ group of maternal genitors might contain one AST allele on average.

Flower gender analysis revealed that around half of the genotypes analyzed have the capacity to generate the male flower (47.4\%). This proportion is as expected, since the crosses need always a parent bearing male flowers. In the IVIA breeding program the presence of male flowers is a discarded trait for all types of fruit. In astringent types as PCA, PVA and PVNA, the presence of male flowers resulted in fruits pollinated and the production of seeds that brown the flesh and difficult the postharvest treatment for removing the astringency. PCNA types are discarded as well because 
consumers do not accept seeds in the fruits and the presence of male flowers can pollinate astringent fruits, affecting negatively the quality and marketability of them.

Combined results of both markers, AST positive (astringency of the fruit) and DISx-AF4S positive (presence of male flowers) resulted in a high number of discarded genotypes. In column (AST- and DISx-AF4S) from Table 2 we indicated the genotypes that will be selected according to our breeding objectives. Only genotypes not astringent (PCNA type) and without male flowers will be selected (absence of both markers), a total of 118 from 441 (26.8\%). It is important to point out that the markers segregated independently. According to the published genome of Diospyros oleifera [34], identified as the diploid D. kaki ancestor, the DNA fragments from which the markers were derived are located in different chromosomes. Therefore, the AST and D1Sx-AF4 markers must segregate independently.

The low rate of genotypes selected from the populations generated indicates the usefulness of the MAS applied in persimmon breeding. We could select at a plantlet stage the genotypes that will be planted in the fields for further agronomic selection. This MAS avoids keeping the future rejected plants during 4 years in the experimental fields. In our case near to $75 \%$ of the genotypes obtained can be discarded at the seedling stage in the greenhouse, indicating a high effectiveness of MAS in persimmon breeding.

\section{Conclusions}

The markers DISx-AF4, linked to the production of male flowers and AST linked to astringency of the fruits, have been validated in a germplasm collection of persimmon. Although the markers were developed from Japanese cultivars, the correlation between the phenotype and genotype was $100 \%$ in germplasm from a different origin, which demonstrated the usefulness of the markers for selecting these important traits. Both markers have been screened in different progenies from a backcross that includes an astringent parent from non-Japanese origin. Results demonstrated that selection of both traits combined resulted in a very low rate of selection. In a context of breeding programs that involve astringent cultivars the MAS applied to discriminate PCNA genotypes is highly valuable.

Author Contributions: Conceptualization, M.B. and M.L.B.; Methodology, M.B. and F.G.-M.; Investigation, M.B. and M.d.M.N.; Writing-Original Draft, M.L.B.; Writing-Review and Editing, M.B., F.G.-M. and M.d.M.N.; Funding Acquisition, M.L.B. and M.B.; Resources, M.L.B.; Supervision, M.L.B. and M.B. All authors have read and agreed to the published version of the manuscript.

Funding: This research was funded by IVIA grant 51914 and partially funded by FEDER. FGM was funded by European Social Fund and Generalitat Valenciana grant ACIF/2016/115.

Conflicts of Interest: The authors declare no conflict of interest.

\section{References}

1. Dellaporta, S.L.; Calderon-Urrea, A. Sex determination in flowering plants. Plant Cell 1993, 5, $1241-1251$. [PubMed]

2. Yonemori, K.; Sugiura, A.; Tanaka, K.; Kameda, K. Floral Ontogeny and Sex Determination in Monoecious-type Persimmons. J. Am. Soc. Hortic. Sci. 1993, 118, 293-297. [CrossRef]

3. Xu, L.Q.; Zhang, Q.L.; Luo, Z.R. Occurrence and cytological mechanism of $2 \mathrm{n}$ pollen formation in Chinese Diospyros spp. (Ebenaceae) staminate germplasm. J. Hortic. Sci. Biotechnol. 2008, 83, 668-672. [CrossRef]

4. Yakushiji, H.; Yamada, M.; Yonemori, K.; Sato, A.; Kimura, N. Staminate flower production on shoots of Fuyu' and "Jiro" persimmon (Diospyros kaki Thunb.). J. Jpn. Soc. Hortic. Sci. 1995, 64, 41-46. [CrossRef]

5. Giordani, E.; Picardi, E.; Radice, S. Morfologia y Fisiologia. In El Cultivo del Caqui; Badenes, M.L., Intrigliolo, D.S., Salvador, A., Vicent, A., Eds.; Generalitat Valenciana: Valencia, Spain, 2015; pp. 17-33; ISBN 9788448260187.

6. Kajiura, M.; Blumenfeld, A. Diospyros kaki. In CRC Handbook of Flowering; Halevy, A.H., Ed.; CRC Press: Boca Raton, FL, USA, 1989; Volume 6, pp. 298-306; ISBN 9781315893464.

7. Yamada, M.; Giordani, E.; Yonemori, K. Persimmon. In Fruit Breeding; Badanes, M.L., Byrne, D.H., Eds.; Springer: New York, NY, USA, 2012; Volume 8, pp. 663-693; ISBN 9781441907639. 
8. Sugiura, A.; Yonemori, K.; Harada, H.; Tomana, T. Changes of ethanol and acetaldehyde contents in Japanese persimmon fruits and their relation to natural deastringency. Stud. Inst. Hortic. Kyoto Univ. 1979, 9, 41-47.

9. Sugiura, A.; Tomana, T. Relationships of ethanol production by seeds of different types of Japanese persimmons and their tannin content. Hort. Sci. 1983, 18, 319-321.

10. Akagi, T.; Kajita, K.; Kibe, T.; Morimura, H.; Tsujimoto, T.; Nishiyama, S.; Kawai, T.; Yamane, H.; Tao, R. Development of molecular markers associated with sexuality in Diospyros lotus L. and their application in D. kaki Thunb. J. Jpn. Soc. Hortic. Sci. 2014, 83, 214-221. [CrossRef]

11. Akagi, T.; Henry, I.M.; Tao, R.; Comai, L. A Y-chromosome-encoded small RNA acts as a sex determinant in persimmons. Science 2014, 346, 646-650. [CrossRef]

12. Yonemori, K.; Matsushima, J. Property of Development of the Tannin Cells in Non-Astringent Type Fruits of Japanese Persimmon (Diospyros kaki) and Its Relationship to Natural Deastringency. J. Jpn. Soc. Hortic. Sci. 1985, 54, 201-208. [CrossRef]

13. Ikeda, I.; Yamada, M.; Kurihara, A.; Nishida, T. Inheritance of Astringency in Japanese Persimmon. J. Jpn. Soc. Hortic. Sci. 1985, 54, 39-45. [CrossRef]

14. Kanzaki, S.; Yamada, M.; Sato, A.; Mitani, N.; Ustunomiya, N.; Yonemori, K. Conversion of RFLP markers for the selection of pollination-constant and non-astringent type persimmons (Diospyros kaki Thunb.) into PCR-based markers. J. Jpn. Soc. Hortic. Sci. 2009, 78, 68-73. [CrossRef]

15. Kono, A.; Kobayashi, S.; Onoue, N.; Sato, A. Characterization of a highly polymorphic region closely linked to the AST locus and its potential use in breeding of hexaploid persimmon (Diospyros kaki Thunb.). Mol. Breed. 2016, 36, 1-13. [CrossRef]

16. Kanzaki, S.; Yonemori, K.; Sugiura, A.; Sato, A.; Yamada, M. Identification of molecular markers linked to the trait of natural astringency loss of Japanese persimmon (Diospyros kaki) fruit. J. Jpn. Soc. Hortic. Sci. 2001, 126, 51-55. [CrossRef]

17. Ikegami, A.; Yonemori, K.; Sugiura, A.; Sato, A.; Yamada, M. Segregation of astringency in F1 progenies derived from crosses between pollination-constant, nonastringent persimmon cultivars. HortScience 2004, 39, 371-374. [CrossRef]

18. Akagi, T.; Takeda, Y.; Yonemori, K.; Ikegami, A.; Kono, A.; Yamada, M.; Kanzaki, S. Quantitative genotyping for the astringency locus in hexaploid persimmon cultivars using quantitative real-time PCR. J. Jpn. Soc. Hortic. Sci. 2010, 135, 59-66. [CrossRef]

19. Kanzaki, S.; Akagi, T.; Masuko, T.; Kimura, M.; Yamada, M.; Sato, A.; Mitani, N.; Ustunomiya, N.; Yonemori, K. SCAR markers for practical application of marker-assisted selection in persimmon (Diospyros kaki Thunb.) breeding. J. Jpn. Soc. Hortic. Sci. 2010, 79, 150-155. [CrossRef]

20. Onoue, N.; Kobayashi, S.; Kono, A.; Sato, A. SSR-based molecular profiling of 237 persimmon (Diospyros kaki Thunb.) germplasms using an ASTRINGENCY-linked marker. Tree Genet. Genomes 2018, 14. [CrossRef]

21. Martínez-Calvo, J.; Naval, M.; Zuriaga, E.; Llácer, G.; Badenes, M.L. Morphological characterization of the IVIA persimmon (Diospyros kaki Thunb.) germplasm collection by multivariate analysis. Genet. Resour. Crop Evol. 2013, 60, 233-241. [CrossRef]

22. Del Naval, M.M.; Zuriaga, E.; Pecchioli, S.; Llácer, G.; Giordani, E.; Badenes, M.L. Analysis of genetic diversity among persimmon cultivars using microsatellite markers. Tree Genet. Genomes 2010, 6, 677-687. [CrossRef]

23. Doyle, J.J.; Doyle, J.L. A rapid DNA isolation procedure for small quantities of fresh leaf tissue. Phytolog. Bull 1987, 19, 11-15. [CrossRef]

24. Soriano, J.M.; Pecchioli, S.; Romero, C.; Vilanova, S.; Llácer, G.; Giordani, E.; Badenes, M.L. Development of microsatellite markers in polyploid persimmon (Diospyros kaki Thunb) from an enriched genomic library. Mol. Ecol. Notes 2006, 6, 368-370. [CrossRef]

25. Besada, C.; Novillo, P.; Navarro, P.; Salvador, A. Causes of flesh browning in persimmon-A review. Acta Hortic. 2018, 1195, 203-210. [CrossRef]

26. Munera, S.; Besada, C.; Blasco, J.; Cubero, S.; Salvador, A.; Talens, P.; Aleixos, N. Astringency assessment of persimmon by hyperspectral imaging. Postharvest Biol. Technol. 2017, 125, 35-41. [CrossRef]

27. Yamada, M. Persimmon Breeding in Japan. Jpn. Agric. Res. Q. 1993, 27, 33-37.

28. Yamada, M.; Sato, A.; Yakushiji, H.; Yoshinaga, K.; Yamane, H.; Endo, M. Characteristics of "Luo Tian Tian Shi", a non-astringent cultivar of oriental persimmon (Diospyros kaki Thunb.) of Chinese origin in relation to non-astringent cultivars of Japanese origin. Bull. Fruit Tree Res. Stn. 1993, 25, 19-32. 
29. Bellini, E.; Giordani, E. Germplasm and breeding of persimmon in Europe. Acta Hortic. 2005, 685, 65-74. [CrossRef]

30. Badenes, M.L.; Martinez-Calvo, J.; Naval, M.M. The persimmon breeding program at IVIA: Alternatives to conventional breeding of persimmon. Acta Hortic. 2013, 996, 71-76. [CrossRef]

31. Luo, Z.; Zhang, Q.; Luo, C.; Xie, F. Recent advances of persimmon research and industry in China. Acta Hortic. 2013, 996, 43-48. [CrossRef]

32. Ma, K.B.; Lee, I.B.; Kim, Y.K.; Won, K.H.; Cho, K.S.; Choi, J.J.; Lee, B.H.N.; Kim, M.S. 'Jowan', an early maturing PCNA (pollination constant non-astringent) persimmon (Diospyros kaki Thunb.). Acta Hortic. 2018, 1195, 61-64. [CrossRef]

33. Mitani, N.; Kono, A.; Yamada, M.; Sato, A.; Kobayashi, S.; Ban, Y.; Ueno, T.; Shiraishi, M.; Kanzaki, S.; Tsujimoto, T.; et al. Application of marker-assisted selection in persimmon breeding of PCNA offspring using SCAR markers among the population from the cross between Non-PCNA 'taigetsu' and PCNA 'kanshu'. HortScience 2014, 49, 1132-1135. [CrossRef]

34. Zhu, Q.G.; Xu, Y.; Yang, Y.; Guan, C.F.; Zhang, Q.Y.; Huang, J.W.; Grierson, D.; Chen, K.S.; Gong, B.C.; Yin, X.R. The persimmon (Diospyros oleifera Cheng) genome provides new insights into the inheritance of astringency and ancestral evolution. Hortic. Res. 2019. [CrossRef] [PubMed]

(C) 2020 by the authors. Licensee MDPI, Basel, Switzerland. This article is an open access article distributed under the terms and conditions of the Creative Commons Attribution (CC BY) license (http://creativecommons.org/licenses/by/4.0/). 